\title{
Vitamin D Status in Saudi Patients with Type 1 Diabetes Mellitus
}

\author{
Khalid Salim Aljabri*, S. A. Bokhari, K. A. Alqurashi \\ Department of Endocrinology, King Fahad Armed Forces Hospital, Jeddah, KSA \\ Email: "khalidsaljabri@yahoo.com \\ Received January 7, 2013; revised February 6, 2013; accepted March 6, 2013
}

Copyright (C) 2013 Khalid Salim Aljabri et al. This is an open access article distributed under the Creative Commons Attribution License, which permits unrestricted use, distribution, and reproduction in any medium, provided the original work is properly cited.

\begin{abstract}
Aims/Introduction: There are studies in different countries regarding the prevalence of vitamin D deficiency in non diabetic population. Few studies were done in adults with type 1 diabetes mellitus. This study was conducted to determine Vitamin D Status among Saudi patients with type 1 diabetes and to correlate the associated environmental risk factors. Materials and Methods: A cross-sectional single centre study was conducted in 221 Saudi patients with type 1 diabetes mellitus. These patients were recruited through the Diabetes Centre at King Fahad Armed Forces Hospital between January 2008 and June 2009. 25-hydroxy-vitamin D, Parathyroid hormone, calcium, phosphate and alkaline phosphatase were measured. Results: There were 221 patients with type 1 diabetes mellitus, 92 males (42\%) and 129 females (58\%). The mean age was $21.3 \pm 7.2$ and the mean diabetes duration was $7.5 \pm 5.7$. The frequency of 25 -hydroxyvitamin $\mathrm{D}<50 \mathrm{nmol} / 1$ and $<25 \mathrm{nmol} / 1$ were $97 \%$ and $60 \%$ respectively. The frequency of 25 -hydroxyvitamin $\mathrm{D}<$ $25 \mathrm{nmol} / 1$ was significantly more frequent in female. $67 \%$ were either only exposed face or totally covered. Duration of sun exposure in $64 \%$ was less than 30 minutes per day. The area of skin exposed and duration of sunlight exposure associated significantly with Vitamin D levels ( $\mathrm{p}<0.0001$ and $\mathrm{p}<0.0001$ respectively). Age was associated with more vitamin $\mathrm{D}<25 \mathrm{nmol} / 1$ (the odds ratio (95\% confidence interval); $4.8(4.6,14.5), \mathrm{p}=0.005 ; 5.3(1.8,15.5), \mathrm{p}=0.003 ; 3.9$ $(1.5,10.5), p=0.007$ for age groups $12-15,16-19$ and $20-24$ years old consequently. Male gender and exposing face, arms and legs to sun were associated with vitamin $\mathrm{D} \geq 25 \mathrm{nmol} / \mathrm{l}$; the odds ratio ( $95 \%$ confidence interval); 0.27 $(0.11,0.6), p=0.001 ; 0.26(0.09,0.75), p=0.01$ consequently. Conclusions: Prevalence of vitamin D deficiency in patients with type 1 diabetes mellitus is high. We recommend to create awareness to increase sunlight exposure and high intake of vitamin D rich food at mass level and starting of Vitamin D food fortification program at government level.
\end{abstract}

Keywords: Type 1 Diabetes Mellitus; Vitamin D Deficiency; Frequency

\section{Introduction}

Type 1 Diabetes mellitus is thought to be the consequence of an autoimmune destruction of the insulin producing beta cell as a result of interactions between different susceptibility genes and environmental exposure [1]. The increasing incidence of type 1 diabetes mellitus strongly suggests the importance of environmental factors; the major factors being pursued incude diet and viruses [2]. Serum 25-hydroxyvitamin D (25(OH)D) concentrations are largely determined by environmental factors, mainly through vitamin D intake and ultraviolet exposure. The sun is the primary source of vitamin D, which is synthesized endogenously in the skin to produce cholecalficerol (vitamin D3), although a small proportion $(<20 \%)$ of vitamin D comes through diet from a limited

${ }^{*}$ Corresponding author. range of foods (in the form of ergocalciferol [vitamin D2] and vitamin D3) [3]. The main marker of vitamin D status is the metabolite $25(\mathrm{OH}) \mathrm{D}$, which is synthesized in the liver $[3,4]$. Deficiency of Vitamin D remains a major health problem in many parts of the world [3]. The relationship between type 1 diabetes mellitus and vitamin $D$ deficiency has been reported to be $15 \%$ to $90.6 \%$ [4-11]. Studies from Saudi Arabia in a cohort of subjects without history of diabetes mellitus showed high prevalence of vitamin D deficiency ranging from $21.9 \%$ to $81 \%$ among children and adolescents school girls respectively $[12,13]$. We conducted a cross sectional study to define Vitamin D Status and the associated environmental risk factors in young patients with type 1 diabetes mellitus.

\section{Materials and Methods}

A cross-sectional single centre study was conducted in 
221 patients with type 1 diabetes mellitus. These patients were recruited randomly through the Diabetes Centre at King Fahad Armed Forces Hospital, Jeddah, Saudi Arabia between January 2008 and June 2009. Eligible patients were older than 12 years old, had type 1 diabetes mellitus [1]. Exclusion criteria were known hepatic or renal disease, metabolic bone disease, malabsorption, hypercortisolism, malignancy, immobility for more than one-week, pregnancy, lactation, and medications influencing bone metabolism. All the patients gave their or their guardian informed consent prior to their inclusion. The study was approved by the ethical board of King Fahad Armed Forces Hospital. The subjects were asked to complete a questionnaire at the time of inclusion. The questionnaire included details of duration of exposure to sun light in previous month (less than 30 minutes/more than 30 minutes/day), clothing (exposure of hand and face or more than). In order to quantify the level of vitamin D and calcium consumption in the previous month, a dietary products frequency was assessed through the intake of dietary products as daily, twice per week or none. Furthermore study subjects were not able to recall quantity of vitamin D containing foodstuff taken by them. Due to these limitations exact estimation of dietary intake of vitamin D was not possible. Any vitamin D or calcium formulation intake was recorded. Height and weight were measured at this stage. Body mass index (BMI) was calculated as weight (kilograms) divided by height squared (square meters). Their health status was assessed by medical conditions, family history, BMI, past or present clinical manifestations, 25(OH)D, Calcium, phosphorus, magnesium, alkaline phosphatase, glycosylated hemglobin, Parathyoid hormone, analysis. The serum level of $25(\mathrm{OH}) \mathrm{D}$ was measured by competitive protein binding assay using kits (Immunodiagnostic, Bensheim, Germany). Vitamin D deficiency was defined as serum 25-OHD levels $<50 \mathrm{nmol} / \mathrm{L}$ while a level $<25 \mathrm{nmol} / \mathrm{L}$ was defined as severe vitamin D deficiency [3]. Glycosylated hemglobin was measured using the high performance liquid chromatography. The serum levels of calcium, phosphate. Magnesium and alkaline phosphatase activity were measured using routine laboratory methods to get additional information about vitamin D status.

\section{Statistical Analysis}

Unpaired t-test was employed to compare single parameters between groups. Chi square $\left(\mathrm{X}^{2}\right)$ test were used for categorical data comparison. For the correlations between environmental factors and vitamin D deficiency, multivariate regression analyses was performed to adjust potential confounders. We fit regression model by specifying full models with potential effect modifiers and confounding variables (age, diabetes duration, $\mathrm{BMI}, \mathrm{HbAlc}$, body parts exposed to sun, duration of sun exposure, intake of diary products and vitamin D or calcium. All statistical analyses were performed using SPSS Version 17.0. All $\mathrm{p}$ values were based on two-sided tests. The difference between groups was considered significant when $\mathrm{p}<0.05$.

\section{Results}

There were 221 patients with type 1 diabetes mellitus, 92 male $(42 \%)$ and 129 female (58\%). The mean age was $21.3 \pm 7.2$ and the mean diabetes duration was $7.5 \pm 5.7$. 25 -hydroxyvitamin $\mathrm{D}<50 \mathrm{nmol} / 1$ and $<25 \mathrm{nmol} / 1$ were found in $97 \%$ and $60 \%$ respectively, Table 1. Figure 1 showed the frequencies of various levels of vitamin D. 25 -hydroxyvitamin $\mathrm{D}<25 \mathrm{nmol} / 1$ was significantly more frequent in female than male, $77 \%$ vs. $37 \%, \mathrm{p}<0.0001$, Table 2. When outdoor most of them either only exposed face or totally covered (67\%). Duration of sun exposure in majority was less than 30 minutes (64\%). Regarding dietary habits most of the participants consumed food good in diary products $(52 \%)$ whereas almost all of them are taken vitamins (97\%), Table 3. Area of skin exposed and duration of sunlight exposure associated significantly with Vitamin D levels $<25 \mathrm{nmol} / 1(\mathrm{p}<0.0001$ and $\mathrm{p}<$ 0.0001 respectively), Figure 2.

Multivariate regression analyses was performed to adjust potential confounders (age, diabetes duration, BMI, HbA1c, body parts exposed to sun, duration of sun exposure, intake of diary products and vitamin $\mathrm{D}$ or calcium),

Table 1. Patient characteristics.

\begin{tabular}{|c|c|c|}
\hline \multicolumn{2}{|c|}{ Parameters } & Values \\
\hline \multicolumn{2}{|c|}{ Numbers } & 221 \\
\hline \multicolumn{2}{|c|}{ Male/female (n (\%)) } & $92(42) / 129(58)$ \\
\hline \multicolumn{2}{|c|}{ Age (years ) } & $21.3 \pm 7.2$ \\
\hline \multicolumn{2}{|c|}{ Body mass index $\left(\mathrm{Kg} / \mathrm{m}^{2}\right)$} & $18.8 \pm 4.6$ \\
\hline \multicolumn{2}{|c|}{ Diabetes duration (years ) } & $7.5 \pm 5.7$ \\
\hline \multicolumn{2}{|c|}{ Calcium $(2.2-2.6 \mathrm{mmol} / \mathrm{L})$} & $2.3 \pm 0.2$ \\
\hline \multicolumn{2}{|c|}{ Phosphorus (0.8 to $1.4 \mathrm{mmol} / \mathrm{l})$} & $1.3 \pm 0.3$ \\
\hline \multicolumn{2}{|c|}{ Magnesium (0.69 - $0.94 \mathrm{mmol} / \mathrm{l})$} & $0.8 \pm 0.1$ \\
\hline \multicolumn{2}{|c|}{ Parathyroid hormone (1.3 - $7.6 \mathrm{pmol} / \mathrm{l})$} & $5.8 \pm 5.1$ \\
\hline \multicolumn{2}{|c|}{ Alkaline phosphatase $(30-115 \mathrm{U} /$ liter $)$} & $136.0 \pm 96.2$ \\
\hline \multicolumn{2}{|c|}{ Glycosylated hemoglobin } & $9.4 \pm 2.3$ \\
\hline \multirow{2}{*}{$\begin{array}{c}\text { 25-hydroxyvitamin D } \\
\text { level }(\mathrm{n}(\%))\end{array}$} & $<25(\mathrm{nmol} / \mathrm{L})$ & $133(60)$ \\
\hline & $<50(\mathrm{nmol} / \mathrm{L})$ & $214(97)$ \\
\hline
\end{tabular}

Data are presented as mean \pm standard deviation with normal laboratory values between brackets. 
Table 2. Results between vitamin D level groups.

\begin{tabular}{|c|c|c|c|}
\hline \multirow{2}{*}{ Parameters } & \multicolumn{2}{|c|}{ 25-hydroxyvitamin D levels (nmol/L) } & \multirow{2}{*}{$\mathbf{p}$ values } \\
\hline & $<25$ & $\geq 25$ & \\
\hline Numbers (\%) & $133(60)$ & $88(40)$ & \\
\hline Male/female (\%) & $37 / 77$ & $63 / 23$ & $<0.0001$ \\
\hline Age (years) & $20.6 \pm 6.4$ & $22.3 \pm 8.2$ & 0.09 \\
\hline Body mass index $\left(\mathrm{Kg} / \mathrm{m}^{2}\right)$ & $18.9 \pm 4.7$ & $18.7 \pm 4.5$ & 0.8 \\
\hline Diabetes duration (years) & $7.8 \pm 5.9$ & $7.2 \pm 5.5$ & 0.5 \\
\hline Calcium & $2.3 \pm 0.2$ & $2.3 \pm 0.1$ & 0.9 \\
\hline Phosphorus & $1.3 \pm 0.3$ & $1.3 \pm 0.3$ & 1.0 \\
\hline Magnesium & $0.8 \pm 0.1$ & $0.8 \pm 0.1$ & 0.5 \\
\hline Parathyroid hormone & $6.4 \pm 5.5$ & $6.1 \pm 9.2$ & 0.03 \\
\hline Alkaline phosphatase & $138.2 \pm 100.5$ & $132.6 \pm 89.4$ & 0.7 \\
\hline Glycosylated hemoglobin & $9.4 \pm 2.2$ & $9.5 \pm 2.5$ & 0.9 \\
\hline
\end{tabular}

Data are presented as mean \pm standard deviation.

Table 3. Relation of age, sun exposure and dietary habits to vitamin $D$ level $<25 \mathrm{nmol} / \mathrm{l}$ in males and females Saudi patients with type 1 diabetes mellitus represented as percentage.

\begin{tabular}{|c|c|c|c|c|c|}
\hline \multirow{2}{*}{\multicolumn{2}{|c|}{ Parameters }} & \multicolumn{3}{|c|}{ Gender } & \multirow{2}{*}{$\mathrm{p}$} \\
\hline & & Total & Male & Female & \\
\hline \multirow{4}{*}{ Age (years) } & $12-15$ & 27 & 45 & 77 & 0.01 \\
\hline & $16-19$ & 22 & 44 & 77 & 0.03 \\
\hline & $20-24$ & 25 & 45 & 80 & 0.009 \\
\hline & $>25$ & 26 & 19 & 73 & $<0.0001$ \\
\hline \multirow{3}{*}{ Body parts exposed to sun } & Face, arms \& legs & 13 & 71 & 29 & 0.08 \\
\hline & Face \& arms & 20 & 35 & 65 & 0.02 \\
\hline & Face only or total coverage & 67 & 14 & 86 & 0.002 \\
\hline \multirow{2}{*}{ Duration of sun exposure } & $>30 \mathrm{~min} /$ day & 36 & 35 & 77 & $<0.0001$ \\
\hline & $<30 \mathrm{~min} /$ day & 64 & 45 & 77 & 0.007 \\
\hline \multirow{3}{*}{ Diary products } & Daily intake & 52 & 33 & 70 & $<0.0001$ \\
\hline & Twice per week & 32 & 36 & 83 & $<0.0001$ \\
\hline & None & 16 & 50 & 89 & 0.04 \\
\hline \multirow{3}{*}{ Sea food } & Daily & 2 & 67 & 0 & 1.0 \\
\hline & Twice weekly & 29 & 44 & 77 & 0.01 \\
\hline & None & 69 & 31 & 77 & $<0.0001$ \\
\hline \multirow{2}{*}{ Vitamins } & Yes & 98 & 36 & 77 & $<0.0001$ \\
\hline & No & 2 & 50 & 50 & 1.0 \\
\hline \multirow{2}{*}{ Drugs } & Yes & 98 & 36 & 77 & $<0.0001$ \\
\hline & No & 2 & 67 & 33 & 1.0 \\
\hline
\end{tabular}




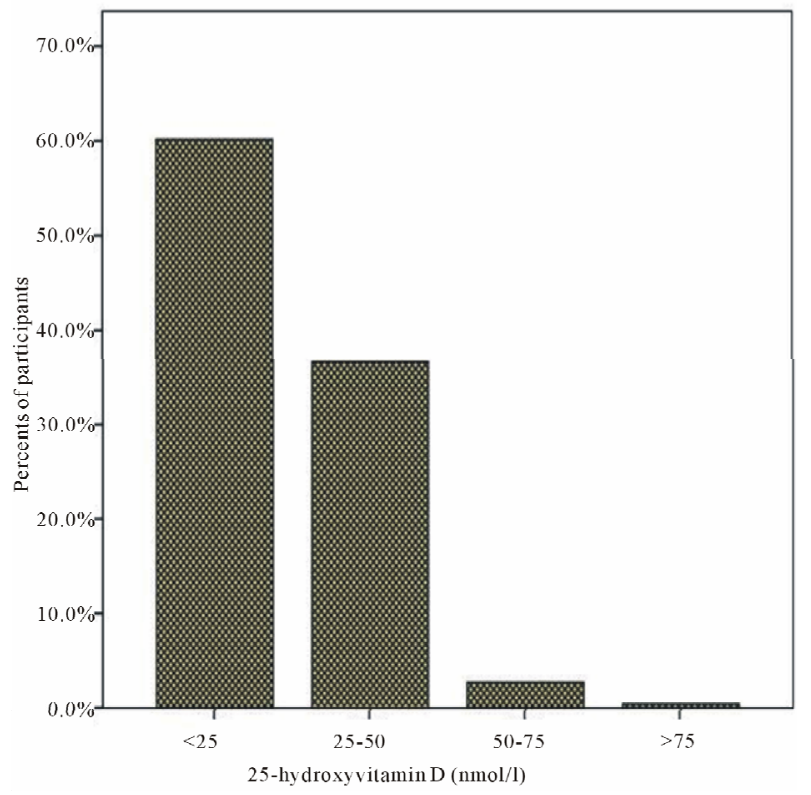

Figure 1. Frequency of variable Vitamin D levels (nmol/l).

age was associated with more vitamin $\mathrm{D}<25 \mathrm{nmol} / 1$ (the odds ratio (95\% confidence interval); $4.8(4.6,14.5), \mathrm{p}=$ $0.005 ; 5.3(1.8,15.5), \mathrm{p}=0.003 ; 3.9(1.5,10.5), \mathrm{p}=$ 0.007 for age groups $12-15,16-19$, and $20-24$ years old consequently. Male gender and exposing face, arms and legs to sun were associated with vitamin $\mathrm{D} \geq 25$ $\mathrm{nmol} / \mathrm{l}$; (the odds ratio ( $95 \%$ confidence interval); 0.27 $(0.11,0.6), p=0.001 ; 0.26(0.09,0.75), p=0.01$ consequently.

\section{Discussion}

Studies in non diabetic population have shown high prevalence of vitamin D deficiency ranging from $44 \%$ $95 \%$ [14-23]. A most important finding is that the frequency of vitamin D deficiency was higher among type 1 diabetes mellitus subjects $(97 \%)$ in Saudis residing in Jeddah despite abundant sunlight throughout the year. It is of importance to state that the sample size is representative for a number of subjects suffering from type 1 diabetes mellitus in the area and study population of one diabetic centre does not represent the entire city of Jeddah, in addition the study sample confined to patients with type 1 diabetes but without comparable groups. A number of studies from different regions of the world have highlighted the high prevalence of vitamin $\mathrm{D}$ deficiency in children with type 1 diabetes mellitus. Greer et al. in Australia, found a three-times higher risk of having levels below $20 \mathrm{ng} / \mathrm{ml}$ in adolescents with newly diagnosed diabetes than in the controls [7]. Another study from Italy examined $25(\mathrm{OH}) \mathrm{D}$ levels in 88 children newly diagnosed with type 1 diabetes mellitus and 57 healthy age- and sex-matched controls. Levels of both
$25(\mathrm{OH}) \mathrm{D}$ were significantly lower in the diabetic adolescents [10]. A recent study from Boston measured 25(OH)D levels in 128 children with established and newly diagnosed type 1 diabetes mellitus. A total of $24 \%$ had levels above $75 \mathrm{nmol} / \mathrm{L}$, but $61 \%$ had levels between 52 to 72 nmol per liter and $15 \%$ were deficient $(<50$ $\mathrm{nmol} / \mathrm{L})$ [24]. Bener et al. compared 25(OH)D levels in 170 age-, race- and sex-matched type 1 diabetes mellitus cases and healthy controls in Qatar, a region with ample sunshine all year round. There was a high prevalence of deficiency/insufficiency ( $<75 \mathrm{nmol} / \mathrm{L}$ ) in both the groups (90.6 vs $85.3 \%$ ), but it was significantly higher in the diabetic children [9]. Janner et al., Of the 129 children and adolescents with type 1 diabetes mellitus, 78 (60.5\%) were vitamin $\mathrm{D}$ deficient, defined as a 25 -hydroxy-vitamin-D level below $50 \mathrm{nmol} / \mathrm{L} \mathrm{[25].}$

In contrast, $25 \mathrm{D}$ levels were usually above $50 \mathrm{nmol} / \mathrm{L}$ in young adults at diagnosis of type 1 diabetes mellitus in Sweden [11]. These overall differences might be explained by the variability of geographical environment, the age of the subjects, duration of diabetes, glycaemic control [24].

The effect of sunlight on Vitamin D status has been well documented and confirms the importance of sunlight exposure in the synthesis of vitamin D [26,27].

Sunlight exposure was the most important determinant of Vitamin D levels in the study population. The area of skin exposed and duration of sunlight exposure associated significantly with Vitamin D levels $(p<0.0001$ and $\mathrm{p}<0.0001$ respectively) in this study as shown similarly by other studies $[14,16,19,22,23,28]$. As dark skin requires more sun exposure than less pigmented skin to produce similar amount of vitamin D [26], it is not surprising that hypovitaminosis $\mathrm{D}$ is so prevalent in this country. Avoidance of sun light due to fear of darkening of skin and covering of whole body religiously or the only exposing face and hands traditionally in female patients when going outdoor were the main attributing factors. Male patients may avoid sun exposure as misconception regarding harmful effects of sunlight and unawareness regarding the source of Vitamin D.

Dietary factor was another determinant of the study regarding high prevalence, the history of Vitamin D rich food and use of calcium and Vitamin D supplements among study subjects were not enough to minimize the high prevalence but some previous studies [14-20] showed no such association whereas other studies [22,23] showed significant correlation. In addition, the true estimation of vitamin D intake was not possible owing to unawareness regarding quantity of consuming diet by participants.

Recent studies have shown that body mass index and body fat content are inversely related to serum $25(\mathrm{OH}) \mathrm{D}$ levels and directly related to PTH levels [29-32], which 

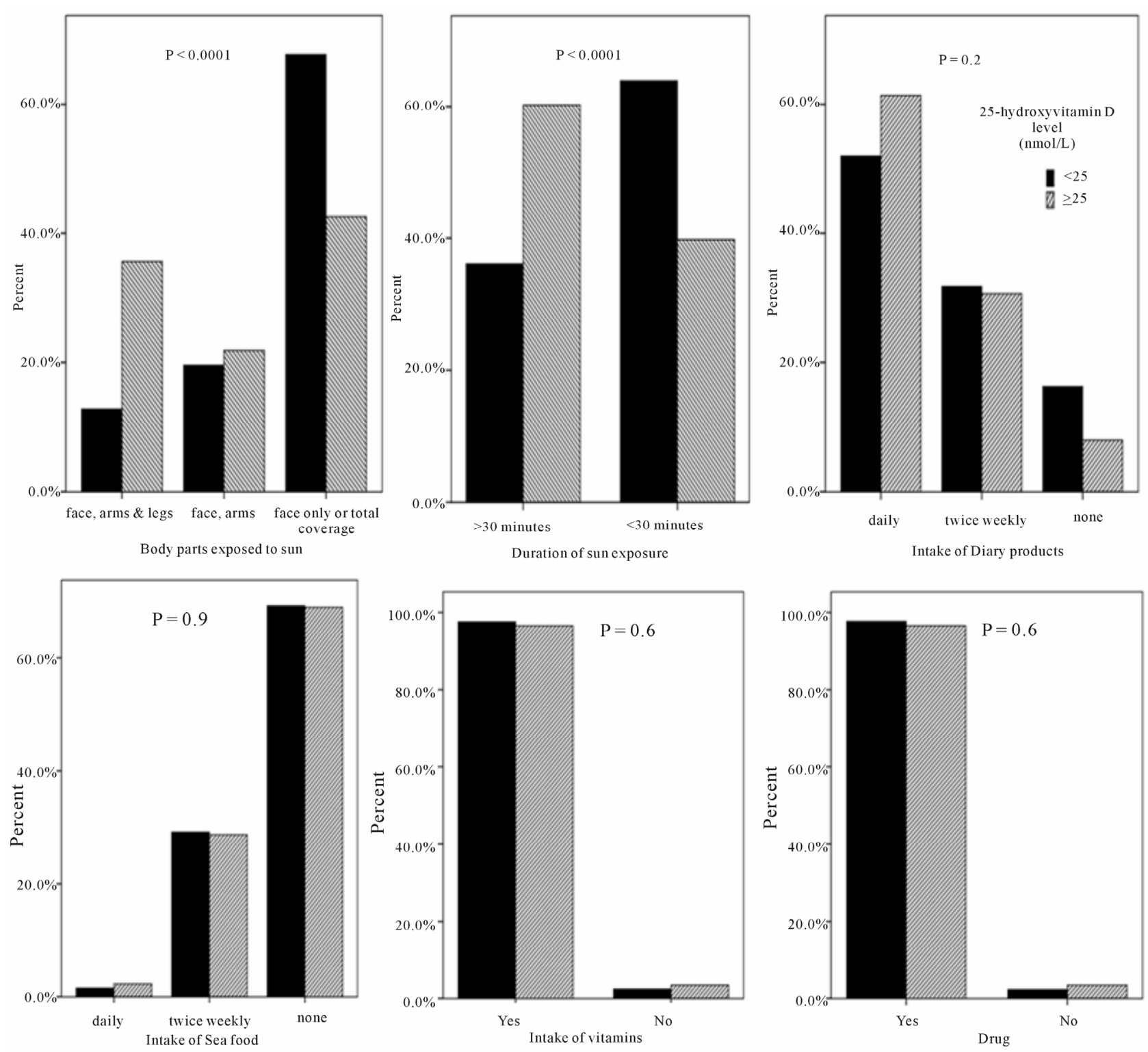

Figure 2. Relation of age, sun exposure and dietary habits to vitamin D level.

is likely due to vitamin D sequestration in body fat compartments. Even slight vitamin D deficiency results in secondary hyperparathyroidism and increased bone resorption $[33,34]$. In adults, PTH levels are expected to rise steeply above $40 \mathrm{pg} / \mathrm{ml}$ at $25 \mathrm{D}$ levels below 50 $\mathrm{nmol} / \mathrm{L}$ and above $50 \mathrm{pg} / \mathrm{ml}$ at $25 \mathrm{D}$ levels below 25 $\mathrm{nmol} / \mathrm{L}$ [35]. We have two possible explanations why PTH levels did not show the expected rise in diabetics. First, the PTH-vitamin D axis has a blunted response in diabetic patients, a finding supported by several studies [36,37]. In one study a blunted response of PTH was associated with low magnesium levels and corrected after magnesium repletion [38]. Our patients, however, did not show any magnesium depletion. A blunted response of PTH would result in inadequately normal PTH levels with low ionised calcium. However, we did not find differences in calcium levels between vitamin D deficient groups.

Limitation of the study: We had several limitations. The study was done at only one centre and was done at one point of time. The study sample confined to patients with type 1 diabetes but without comparable groups. Duration of sun exposure was based on recall rather than actual. We were not able to calculate the daily dietary intake of vitamin D due to several reasons.

In conclusion, Prevalence of vitamin D deficiency in patients with Type 1 diabetes is high. We recommend to create awareness to increase sunlight exposure and high intake of vitamin D rich food at mass level and starting of Vitamin D food fortification program at government level. 


\section{Acknowledgements}

There is no any financial support or relationships that may pose conflict of interest.

\section{REFERENCES}

[1] American Diabetes Association, "Diagnosis and Classification of Diabetes Mellitus," Diabetes Care, Vol. 33, Suppl. 1, 2011, pp. S62-S69.

[2] G. S. Eisenbarth, "Update in Type 1 Diabetes," Journal of Clinical Endocrinology \& Metabolism, Vol. 92, No. 7, 2007, pp. 2403-2407. doi:10.1210/jc.2007-0339

[3] M. F. Holick, "High Prevalence of Vitamin D Inadequacy and Implications for Health," Mayo Clinic Proceedings, Vol. 81, No. 3, 2006, pp. 353-373. doi:10.4065/81.3.353

[4] C. Mathieu and K. Badenhoop, "Vitamin D and Type 1 Diabetes Mellitus: State of the Art," Trends in Endocrinology \& Metabolism, Vol. 16, No. 6, 2005, pp. 261-267. doi:10.1016/j.tem.2005.06.004

[5] K. Luong, L. T. Nguyen and D. N. Nguyen, "The Role of Vitamin D in Protecting Type 1 Diabetes Mellitus," Diabetes/Metabolism Research and Reviews, Vol. 21, No. 4, 2005, pp. 338-346. doi:10.1002/dmrr.557

[6] C. Mathieu, C. Gysemans, A. Giulietti and R. Bouillon, "Vitamin D and Diabetes," Diabetologia, Vol. 48, No. 7, 2005, pp. 1247-1257. doi:10.1007/s00125-005-1802-7

[7] R. M. Greer, M. A. Rogers, F. G. Bowling, H. M. Buntain, M. Harris, G. M. Leong and A. M. Cotterill, "Australian Children and Adolescents with Type 1 Diabetes Have Low Vitamin D Levels," Medical Journal of Australia, Vol. 187, No. 1, 2007, pp. 59-60.

[8] B. M. Svoren, L. K. Volkening, J. R. Wood and L. M. Laffel, "Significant Vitamin D Deficiency in Youth with Type 1 Diabetes Mellitus," Journal of Pediatrics, Vol. 154, No. 1, 2009, pp. 132-134. doi:10.1016/j.jpeds.2008.07.015

[9] A. Bener, A. Alsaied, M. Al-Ali, A. Al-Kubaisi, B. Basha, A. Abraham, G. Guiter and M. Mian, "High Prevalence of Vitamin D Deficiency in Type 1 Diabetes Mellitus and Healthy Children," Acta Diabetologica, Vol. 46, No. 3, 2008, pp. 183-189.

[10] P. Pozzilli, "Low Levels of 25-Hydroxyvitamin D3 and 1,25 Dihydroxy Vitamin D3 in Patients with Newly Diagnosed Type 1 DM," Hormone and Metabolic Research, Vol. 37, No. 11, 2005, pp. 680-683. doi: $10.1055 / \mathrm{s}-2005-870578$

[11] B. Littorin, P. Blom, A. Schölin, H. J. Arnqvist, G. Blohmé, J. Bolinder, A. Ekbom-Schnell, J. W. Eriksson, S. Gudbjörnsdottir, L. Nyström, J. Ostman and G. Sundkvist, "Lower Levels of Plasma 25-Hydroxy D among Young Adults at Diagnosis of Autoimmune Type 1 Diabetes Compared with Control Subjects: Results from the Nationwide Diabetes Incidence study in Sweden (DISS)," Diabetologia, Vol. 49, No. 12, 2006, pp. 2847-2852. doi:10.1007/s00125-006-0426-x

[12] S. H. Sedrani, "Vitamin D Status of Saudis III. Prevalence of Inadequate Plasma 25-Hydroxyvitamine D Concentrations," Saudi Medical Journal, Vol. 13, 1992, pp.
214-219.

[13] A. M. Siddiqui and H. Z. Kamfar, "Prevalence of Vitamin D Deficiency Rickets in Adolescent School Girls in Western Region," Saudi Medical Journal, Vol. 28, No. 3, 2007, pp. 441-444.

[14] S. Hashemipour, B. Larijani, H. Adibi, E. Javadi, M. Sedaghat and M. Pajouhi, "Vitamin D Deficiency and Causative Factors in the Population of Tehran," BMC Public Health, Vol. 4, No.1, 2004, p. 38.

[15] X. Du, H. Greenfield and D. R. Fraser, "Vitamin D Deficiency and Associated Factors in Adolescent Girl in Beijing," American Journal of Clinical Nutrition, Vol. 74, 2001, pp. 494-500.

[16] F. Alagol, Y. Shihadeh and H. Boztepe, "Sunlight Exposure and Vitamin D in Turkish Women," Journal of Endocrinological Investigation, Vol. 23, 2000, pp. 173-177.

[17] R. Goswami, N. Gupta, D. Goswami, R. K. Marwaha, N. Tandon and N. Kochupillai, "Prevalence and Significance of Low 25-Hydroxy Vitamin D Concentrations in Healthy Subjects in Dehli," American Journal of Clinical Nutrition, Vol. 72, 2000, pp. 422-475.

[18] A. Sachan, R. Gupta and V. Das, "High Prevalence of Vitamin D Deficiency among Pregnant Women and Their Newborns in Northern India," American Journal of Clinical Nutrition, Vol. 81, 2005, pp. 1060-1064.

[19] M. H. Gannage-Yared, R. Chemali, N. Yaacoub and G. Halaby, "Hypovitaminosis D in a Sunny Country: Relation to Lifestyle and Bone Markers," Journal of Bone and Mineral Metabolism, Vol. 15, No. 9, 2000, pp. 1856-1862. doi:10.1359/jbmr.2000.15.9.1856

[20] A. A. Mishal, "Effects of Different Dress Styles on Vitamin D Levels in Healthy Young JORDANIAN Women," Osteoporosis International, Vol. 12, No. 11, 2001, pp. 931-935. doi:10.1007/s001980170021

[21] S. Al Faraj and K. Al Mutairi, "Vitamin D Deficiency and Chronic Low Back Pain in Saudi Arabia," Spine, Vol. 28, No. 2, 2003, pp. 177-179. doi:10.1097/00007632-200301150-00015

[22] M. Moussavi, R. Heidarpur and A. Aminorroaya, "Prevalence of Vitamin D Deficiency in Isfahani High School Students in 2004," Hormone Research, Vol. 64, 2005, 144-148. doi:10.1159/000088588

[23] N. Meddeb, H. Sahli and M. Chahed, "Vitamin D Deficiency in Tunisia," Osteoporosis International, Vol. 16, No. 2, 2005, pp. 180-183. doi:10.1007/s00198-004-1658-6

[24] B. M. Svoren, L. K. Volkening, J. R. Wood and L. M. Laffel, "Significant Vitamin D Deficiency in Youth with Type 1 Diabetes Mellitus," Journal of Pediatrics, Vol. 154, No. 1, 2009, pp. 132-134. doi:10.1016/j.jpeds.2008.07.015

[25] M. Janner, P. Ballinari, P. Mullis and C. Flück, "High Prevalence of Vitamin D Deficiency in Children and Adolescents with Type 1 Diabetes," Swiss Medical Weekly, Vol. 140, 2010, Article ID: w13091.

[26] G. L. Saraiva, M. S. Cendoroglo and L. R. Ramos, "Influence of Ultraviolet Radiation on the Production of 25 Hydroxyvitamin D in the Elderly Population in the City 
of Sao Paulo (23 Degrees 342 S), Brazil," Osteoporosis International, Vol. 16, No. 12, 2005, pp. 1649-1654. doi:10.1007/s00198-005-1895-3

[27] R. Bouillon, "Vitamin D. Photosynthesis, Metabolism, and Action to Clinical Applications," In: L. De Groot, J. L. Jameson and H. G. Burger, Eds., Endocrinology, 3rd Edition, Saunders, Philadelphia, 2001, pp. 1009-1028.

[28] M. Z. Islam, M. Akhtaruzzaman and C. Lamberg-Allardt, "Hypovitaminosis D Is Common in both Veiled and Nonveiled Bangladeshi Women," Asia Pacific Journal of Clinical Nutrition, Vol. 15, 2006, pp. 81-87.

[29] J. Wortsman, L. Y. Matsuoka, T. C. Chen, Z. Lu and M. F. Holick, "Decreased Bioavailability of Vitamin D in Obesity," American Journal of Clinical Nutrition, Vol. 72, 2000, pp. 690-693.

[30] M. B. Snijder, R. M. van Dam, M. Visser, et al., "Adiposity in Relation to Vitamin D Status and Parathyroid Hormone Levels: A Population-Based Study in Older Men and Women," Journal of Clinical Endocrinology \& Metabolism, Vol. 90, No. 7, 2005, pp. 4119-4123. doi:10.1210/jc.2005-0216

[31] S. Arunabh, S. Pollack, J. Yeh and J. F. Aloia, "Body Fat Content and 25-Hydroxyvitamin D Levels in Healthy Women," Journal of Clinical Endocrinology \& Metabolism, Vol. 88, No. 1, 2003, pp. 157-161. doi: $10.1210 /$ jc. $2002-020978$

[32] N. H. Bell, S. Epstein, A. Greene, J. Shary, M. J. Oexmann and S. Shaw, "Evidence for Alteration of the Vitamin D-Endocrine System in Obese Subjects," Journal of Clinical Investigation, Vol. 76, No. 1, 1985, pp. 370-373.
doi:10.1172/JCI111971

[33] A. M. Parfitt, J. C. Gallagher, R. P. Heaney, C. C. Johnston, R. Neer and G. D. Whedon, "Vitamin D and Bone Health in the Elderly," American Journal of Clinical Nutrition, Vol. 36, Suppl. 5, 1982, pp. 1014-1031.

[34] M. Peacoak, "Effect of Calcium and Vitamin D Insufficiency on the Skeleton," Osteoporosis International, Vol. 8, No. 2, 1998, pp. S45-S51. doi:10.1007/PL00022733

[35] M. K. Thomas, D. M. Lloyd-Jones, R. I. Thadhani, A. C. Shaw, D. J. Deraska, B. T. Kitch, et al., "Hypovitaminosis D in Medical Inpatients," New England Journal of Medicine, Vol. 338, 1998, pp. 777-783. doi:10.1056/NEJM199803193381201

[36] N. Fogh-Andersen, P. McNair, J. Moller-Petersen and S. Madsbad, "Lowered Serum Ionized Calcium in Insulin Treated Diabetic Subjects," Scandinavian Journal of Clinical \& Laboratory Investigation, Vol. 165, 1983, pp. 9397.

[37] P. Schwarz, H. A. Sorensen, G. Momsen, T. Friis, I. Transbol and P. McNair, "Hypocalcemia and Parathyroid Hormone Responsiveness in Diabetes Mellitus: A Tri-Sodium-Citrate Clamp Study," Acta Endocrinologica (Copenhagen), Vol. 126, 1992, pp. 260-263.

[38] G. Saggese, G. Federico, S. Bertelloni, G. I. Baroncelli and L. Calisti, "Hypomagnesemia and the Parathyroid Hormone-Vitamin D Endocrine System in Children with Insulin-Dependent Diabetes Mellitus: Effects of Magnesium Administration," Journal of Pediatrics, Vol. 118, No. 2, 1991, pp. 220-225. doi:10.1016/S0022-3476(05)80486-X 